\title{
Expression control and specificity of the basic amino acid exporter LysE of Corynebacterium glutamicum
}

\author{
A. Bellmann, ${ }^{1}$ M. Vrljić, ${ }^{1}$ M. Pátek ${ }^{2}$ H. Sahm, ${ }^{1}$ R. Krämer ${ }^{3}$ \\ and L. Eggeling ${ }^{1}$
}

Author for correspondence: L. Eggeling. Tel: +492461 61 5132. Fax: +49 2461612710. e-mail: l.eggeling@fz-juelich.de

\footnotetext{
1 Institut für Biotechnologie, Forschungszentrum Jülich GmbH, D-52425 Jülich, Germany

2 Institute of Microbiology, Academy of Sciences, CZ-14220 Prague, Czech Republic

3 Institut für Biochemie, Universität zu Köln, Zülpicher Strasse 47, D-57674 Köln, Germany
}

\begin{abstract}
LysE of Corynebacterium glutamicum belongs to a large new superfamily of translocators whose members are probably all involved in the export of small solutes. Here, the transcript initiation site of $l y s E$, and its divergently transcribed regulator gene, lysG, are identified. Single-copy transcriptional fusions of lysE with lacZ, and titration experiments, show that LysG is the positive regulator of lysE expression enabling its up to 20-fold induction. This induction requires the presence of a coinducer, which is either intracellular Llysine, or L-arginine. A competition experiment showed that LysE exports these two basic amino acids at comparable rates of about $0.75 \mathrm{nmol} \mathrm{min}^{-1}(\mathrm{mg}$ dry wt) ${ }^{-1}$. Although L-histidine and L-citrulline also act as coinducers of lysE expression, these two amino acids are not exported by LysE. As is evident from the analysis of a lysEG deletion mutant, the physiological role of the lysEG system is to prevent bacteriostasis due to elevated L-lysine or L-arginine concentrations that arise during growth in the presence of peptides or in mutants possessing a deregulated biosynthesis pathway. C. glutamicum has additional export activities other than those of LysE for exporting L-histidine, L-citrulline and L-ornithine.
\end{abstract}

Keywords : carrier, transcriptional regulator, LTTR, basic amino acid export, peptide hydrolysis

\section{INTRODUCTION}

We are engaged in studying the physiology of Corynebacterium glutamicum, which is used industrially for the production of amino acids (Leuchtenberger, 1996). Together with the genera Mycobacteria and Nocardia, this bacterium belongs to the CMN group of the Grampositive eubacteria. About $4 \times 10^{5}$ tons per year of Llysine are produced using C. glutamicum. Lysine synthesis has therefore been studied thoroughly, and its regulation is sufficiently well understood that it can be overcome in order to achieve production (Cremer et al., 1991; Eggeling et al., 1996). Surprisingly, the extracellular accumulation of L-lysine is determined not only by the properties of its biosynthetic pathway, but also by the properties of its efflux from the cell (an active process driven by the membrane potential) (Bröer \& Krämer, 1991). We were able to isolate mutants with modified efflux (Vrljić et al., 1995) and thus we succeeded in cloning $l y s E$, the gene encoding the L-lysine export carrier (Vrljić et al., 1996).
Studies on the physiological function of $l y s E$ showed that, in the absence of the carrier, L-lysine can reach an intracellular concentration of more than $1100 \mathrm{mM}$, which prevents cell growth. Therefore, in addition to the synthesis of this amino acid, its export apparently also represents a possible means of regulating its intracellular concentration. Such a mechanism, not previously known in bacteria, is necessary in the wildtype of C. glutamicum if lysine-containing peptides are present in the environment (Erdmann et al., 1993). Thus, LysE serves as a valve for exporting excess L-lysine that might be harmful to the cell. Nothing is yet known about the specificity of LysE and its expression control.

In addition to its novel function, the carrier LysE also represents a novel type of structure within the membrane proteins (Vrljić et al., 1999). It is a rather short polypeptide of 233 amino acyl residues which might span the membrane five times. The carrier is therefore a prototype of a new group of translocators, termed the LysE superfamily 
(Genome analysis: comparison of the transport capabilities of several bacteria. M. Saier's transport classification page; http://www.biology.ucsd.edu/ $\sim$ msaier/transport/titlepage.html); members of this large superfamily are present in eubacteria and archaea (Aleshin et al., 1999). They all have a very similar structure, and are possibly all involved in the export of small solutes. Most interestingly, in Escherichia coli there are five paralogues present which might also be related to amino acid export. One of the paralogues confers resistance to L-threonine upon overexpression of the corresponding gene $(r h t C)$, and another one $(r h t B)$ confers resistance to L-homoserine and L-homoserine lactone (Zakataeva et al., 1999). Recently, another exporter of $E$. coli has been identified ( $y d e D)$, related to the export of cysteine or cysteine-related compounds, but not belonging to the LysE superfamily (Daßler et al., 2000).

Since export mediated by carriers belonging to the LysE superfamily is obviously of relevance both to an understanding of basic microbial functions and to biotechnological applications, here we discuss expression control of $l y s E$ and the substrate specificity of the carrier.

\section{METHODS}

Bacteria, plasmids and growth conditions. The strains and plasmids used in this work are listed in Table 1. Luria-Bertani (LB) medium was used as a complex medium for E. coli, and also for C. glutamicum in the case of DNA isolation. For the measurement of $\beta$-galactosidase activities, C. glutamicum was cultivated on either brain-heart infusion (BHI) medium (Difco) or salt medium CGXII (Keilhauer et al., 1993). To inoculate the latter medium, $1 \mathrm{ml}$ of a $5 \mathrm{ml}$ overday $\mathrm{BHI}$ preculture was used first to inoculate an overnight preculture of $50 \mathrm{ml}$ CGXII, which, after being washed with $50 \mathrm{ml}$ cold CGXII, was finally used to inoculate the main culture. When appropriate, ampicillin $\left(50 \mu \mathrm{g} \mathrm{ml}^{-1}\right)$, kanamycin (25 or $\left.50 \mu \mathrm{g} \mathrm{ml}^{-1}\right)$, chloramphenicol $\left(15 \mu \mathrm{g} \mathrm{m}^{-1}\right)$ or nalidixic acid $\left(50 \mu \mathrm{g} \mathrm{ml}^{-1}\right)$ was added. E. coli was grown at $37^{\circ} \mathrm{C}$ and $C$. glutamicum at $30^{\circ} \mathrm{C}$.

Strain and plasmid constructions. The plasmid constructions were made in E. coli DH5 $5 \mathrm{MCR}$. C. glutamicum was transformed via electroporation (Liebl et al., 1989) or, in the case of vector integration into the chromosome, by intergeneric conjugation with E. coli S17-1 (Schäfer et al., 1990). All transformants and transconjugants were analysed by plasmid analysis or PCR, respectively, with appropriate primers annealing in the chromosome and the integrated vector. For chromosomal deletions, double selection was required, which was done according to Schäfer et al. (1994) using kanamycin resistance for the selection of vector integration, with subsequent selection for loss of vector sequences by sucrose resistance based on the absence of vector-encoded $s a c B$. Clones were checked at each step by kanamycin and sucrose resistance/sensitivity and verified by PCR analyses.

Plasmid pEM1dppc with the lysGE'lacZ fusion cassette was made by inserting lac $Z$ with its ribosome-binding site obtained as an Asp718-XbaI fragment (3078 bp) from piWiT10 (Wilcken-Bergmann et al., 1986) into the RsrII site of pJClysGE (Vrljić et al., 1996). The resulting lysGE'lacZ cassette (the BamHI cassette) with a lysE'lacZ transcriptional fusion at nt 62 of $l y s E$ was excised as a BamHI fragment and ligated with BamHI-digested pEM1dppc (Vašicová et al., $1998)$ to give pEM1dppclysGE'lacZ. Plasmid pEM1dppclys $G^{\text {NarI }} E^{\prime} l a c Z$ was made by deletion of the 739 bp NarI fragment of $l y s G$ in $\mathrm{pJClys} G E^{\prime} l a c Z$, re-ligation, and further processing of the resulting $B a m \mathrm{HI}$ cassette as described above. By XhoI-StuI digestion of pJClys GE'lacZ, Klenow treatment, and blunt-end ligation, a Bam HI cassette was made to generate pEM1dppclys $G^{S t u \mathrm{I}-X h o \mathrm{I}} E^{\prime} l a c Z$ deleted of $567 \mathrm{nt}$ within lys $G$. To construct $\mathrm{pK} 18 \mathrm{mobsacB} \Delta l y s A$, the $l y s A$ gene was obtained as a $1.3 \mathrm{~kb}$ Pst I fragment from pCT4-1, which was ligated with pUC18. The resulting vector was restricted with DraIII and EcoRV (deletion of the central $881 \mathrm{bp}$ fragment) and religated. The remaining $560 \mathrm{bp}$ fragment of $\Delta l y s A$ was obtained by restriction with SalI and PstI and ligated with SalI-PstIrestricted $\mathrm{pK} 18$ mobsacB. Plasmid $\mathrm{pK} 18 \mathrm{mobarg}_{\text {int }}$ was made by amplifying a $551 \mathrm{nt}$ internal fragment of $\arg F$ by using primers to which EcoRI and PstI restriction sites were attached. The resulting fragment was ligated with EcoRI-PstIrestricted pUC18, excised by restriction with EcoRI and HindIII, and ligated with EcoRI-HindIII-treated pK18mob. To construct plasmid pEC7lysE, the primers 5'-CTCGAGAGCGGATCCGCGCTGACTCAC-3' and 5'-GGAGAGTACGGCCCATCCACCGTGACC-3' were used to amplify $l y s E$ as a $1.0 \mathrm{~kb}$ fragment with attached $B a m \mathrm{HI}$ sites from pJClysGE, before ligating it with pEC7 (Eikmanns et al., 1991). Overexpression of $l y s E$ was verified by increased Llysine export activity with strain $13032 \Delta \mathrm{GE}$.

RNA analysis. Total RNA was isolated from C. glutamicum clones harbouring the plasmids pET2PlysE or pET2Plys $G$ as described by Börmann et al. (1992). For primer extension experiments, $30 \mu \mathrm{g}$ RNA was hybridized to $0.5 \mathrm{pmol}$ fluorescein-labelled primer (5'-GAAAATCTCGTCGAAGCTCG-3') complementary to vector sequences (Vašicová et al., 1998). Denaturation, annealing and reverse transcription were as described by Peters-Wendisch et al. (1998), and the products were analysed by using an automated laser fluorescence DNA sequencer with sequencing reactions carried out in parallel.

Assay of amino acid export. For the determination of export rates in short-term experiments, pre-grown cells were washed twice with ice-cold CGXII and used to inoculate new CGXII. After growth overnight, the cells were harvested by centrifugation $(5000 \mathrm{~g}, 10 \mathrm{~min})$, washed again (twice with ice-cold CGXII), then amino acid excretion was initiated by resuspending the cells in pre-warmed CGXII containing $2 \mathrm{mM}$ of the appropriate dipeptide (see Results). The resulting cell density $\left(\mathrm{OD}_{600}\right)$ was $8-10$, corresponding to $2 \cdot 4-3.0 \mathrm{mg}$ dry weight $\mathrm{ml}^{-1}$. The cells were stirred and incubated at $30^{\circ} \mathrm{C}$. Samples for silica oil centrifugation (Klingenberg \& Pfaff, 1977) were taken after $1.5 \mathrm{~min}$ and then every $15 \mathrm{~min}$ for a period of $1.25 \mathrm{~h}$. The procedures for deriving cellular and extracellular fractions and for the quantification of the amino acids as their $o$-phthaldialdehyde derivatives via HPLC were as described by Bröer \& Krämer (1991).

Determination of the specific $\beta$-galactosidase activity. For the determination of the specific $\beta$-galactosidase activity, pregrown cells (BHI; Difco) were transferred into BHI medium and cultivated for $4 \mathrm{~h}$ at $30^{\circ} \mathrm{C}$. After the cells had been harvested by centrifugation $(5000 \mathrm{~g}, 10 \mathrm{~min})$, they were washed with ice-cold $0 \cdot 1 \mathrm{M}$ potassium phosphate buffer, $\mathrm{pH} 7 \cdot 0$, centrifuged $(5000 \mathrm{~g}, 10 \mathrm{~min})$, resuspended in $1 \mathrm{ml} \beta$ galactosidase reaction buffer $(5 \mathrm{mM}$ Tris, $\mathrm{pH} 7.5 ; 5 \%$ glycerol; $10 \mathrm{mM} \mathrm{KCl}$ ) and disrupted by sonication in the same buffer. After pelleting of the cellular debris by centrifugation 
Table 1. Strains and plasmids used in this study

\begin{tabular}{|c|c|c|}
\hline Strain/plasmid & Relevant characteristics & Source/reference \\
\hline \multicolumn{3}{|l|}{ Strains } \\
\hline \multicolumn{3}{|l|}{ Escherichia coli } \\
\hline DH $5 \propto \mathrm{MCR}$ & Cloning strain & Grant et al. (1990) \\
\hline S17-1 & Mobilizing donor strain & Simon et al. (1983) \\
\hline \multicolumn{3}{|l|}{ Corynebacterium glutamicum } \\
\hline $13032 \Delta \mathrm{EG}$ & Wild-type deleted of the $S t u \mathrm{I}-M l u \mathrm{I}$ fragment of $l y s E G$ & Vrljić et al. (1996) \\
\hline 13032 $\mathrm{EG}:$ : lys $G E^{\prime} l a c Z$ & $\begin{array}{l}\text { Deletion mutant with } l y s G E^{\prime} l a c Z \text { cassette integrated at } \\
\text { the } \mathrm{d} p p c \text { site }\end{array}$ & This work \\
\hline $13032 \Delta \mathrm{EG}::$ lys $G^{\text {Narr }} E^{\prime} l a c Z$ & Deletion mutant with cassette deleted of $739 \mathrm{nt}$ of $l y s G$ & This work \\
\hline 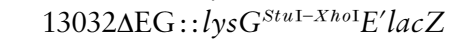 & Deletion mutant with cassette deleted of $567 \mathrm{nt}$ of $l y s G$ & This work \\
\hline $13032 \Delta l y s A$ & Wild-type with $560 \mathrm{bp}$ of lys A deleted & This work \\
\hline $13032:: \arg F$ & Wild-type with $\arg F$ disrupted by $\mathrm{pK} 18 \mathrm{mob} \arg F_{\text {int }}$ & This work \\
\hline MH20-22B & Lysine producer, lys $C(\mathrm{Fbr})$ & Schrumpf et al. (1992) \\
\hline MH20-22B: : lys GE'lacZ & Producer with $l y s G E^{\prime} l a c Z$ cassette integrated & This work \\
\hline LE4 & Isogenic to $\mathrm{MH} 20-22 \mathrm{~B}$, but wild-type $l y s C$ & Schrumpf et al. (1992) \\
\hline LE4::lysGE'lacZ & LE4 with $l y s G E^{\prime} l a c Z$ cassette integrated & This work \\
\hline \multicolumn{3}{|l|}{ Plasmids } \\
\hline pEM1dppc & Vector with $\mathrm{d} p p c$ integration site & Vašicová et al. (1998) \\
\hline pEM1dppclysGE'lacZ & pEM1dppc with lys GE'lacZ cassette & This work \\
\hline pEM1dppclys $G^{N a r \mathrm{I}} E^{\prime} l a c Z$ & $\begin{array}{l}\text { pEM1dppc with cassette deleted of the } 739 \text { nt NarI } \\
\text { fragment }\end{array}$ & This work \\
\hline pEM1dppclys $G^{S t u \mathrm{I}-X h o \mathrm{I}} E^{\prime} l a c Z$ & $\begin{array}{l}\text { pEM1dppc with cassette deleted of the } 567 \mathrm{nt} S t u \mathrm{I}-X h_{0} \mathrm{I} \\
\text { fragment }\end{array}$ & This work \\
\hline pEC7 & Shuttle vector, $\mathrm{Cm}^{\mathrm{R}}$ & Eikmanns et al. (1991) \\
\hline pEC7lysE & pEC7 carrying $l y s E$ as a $1.06 \mathrm{~kb} \mathrm{BamHI}$ fragment & This work \\
\hline pK18mobsacB & Integration vector, $\mathrm{Km}^{\mathrm{R}}$ ori $\mathrm{V}_{\text {E.c. }}$ oriT, $s a c B$ & Schäfer et al. (1994) \\
\hline pJClysGE & pJC1::2.4 kb BamHI insert containing $l y s G$ and $l y s E$ & Vrljić et al. (1996) \\
\hline pET2 & Promoter probe vector & Vašicová et al. (1998) \\
\hline pETPlysE & pET2 with 198 bp fragment of ' $G E$ ' & This work \\
\hline pETPlys $G$ & As pETPlysE, but inverse orientation & This work \\
\hline pVWEx2 & Expression vector, Tet $^{\mathrm{R}}, \operatorname{lacl}^{\mathrm{q}}, t a c$ promoter & Wendisch (1997) \\
\hline pVWEx2'GE' & pVWEx2::455 bp intergenic fragment of lysEG & This work \\
\hline pK18mobsacB $\Delta l y s A$ & $\begin{array}{l}\text { pK18mobsacB with lys } A \text { deleted of a } 560 \text { bp internal } \\
\text { fragment }\end{array}$ & This work \\
\hline pK18mobargF $F_{\text {int }}$ & pK18mob with $551 \mathrm{bp}$ internal fragment of $\arg F$ & This work \\
\hline piWiT10 & Source of lacZ & Wilcken-Bergmann et al. (1986) \\
\hline pCT4-1 & Shuttle vector with lysAargS & Cremer et al. (1991) \\
\hline
\end{tabular}

$\left(5000 \mathrm{~g}, 10 \mathrm{~min}, 4^{\circ} \mathrm{C}\right.$ ) the supernatant was immediately used for the enzyme assay. The specific activity is given in $U$ (mg protein $)^{-1}$.

\section{RESULTS}

\section{LysG is a positive regulator of lysE transcription}

The gene $l y s G$ is located upstream of the carrier gene lysE (Fig. 1). The features of $l y s G$, which is divergently transcribed from $l y s E$ and whose deduced polypeptide exhibits similarities to LTTR-type regulators of Gramnegative bacteria (Schell, 1993), suggest that it is involved in the control of $l y s E$ transcription. To quantify the $l y s G$ effects on the expression of $l y s E$, the fusion cassette lysGE'lacZ was made, carrying the putative regulator, as well as the intergenic region, and the carrier gene fused with lacZ. This fusion cassette was integrated downstream of the $p p c$ gene (Eikmanns et al., 1989) into the chromosome of the wild-type derivative $13032 \Delta \mathrm{GE}$, thus providing the gene locus under study in one single copy. With this strain $(13032 \Delta \mathrm{GE}::$ lys$G E^{\prime}$ lac $Z$ ), a high $\beta$-galactosidase activity of $6.49 \mathrm{U} \mathrm{mg}^{-1}$ was obtained (Fig. 1). When the same fusion cassette was first deleted of most of its lys $G$ sequences by excision of the $739 \mathrm{bp}$ NarI fragment and then integrated into the genome of $13032 \Delta \mathrm{GE}$, a drastically reduced $\beta$ galactosidase activity of only $0.33 \mathrm{U} \mathrm{mg}^{-1}$ was the result. This indicates that the presence of $l y s G$ is essential for increased expression of $l y s E^{\prime} l a c Z$. Interestingly, with a separate StuI-XhoI deletion construct in which an apparent helix-turn-helix motif within LysG is still present, we repeatedly quantified a weak, but sig- 


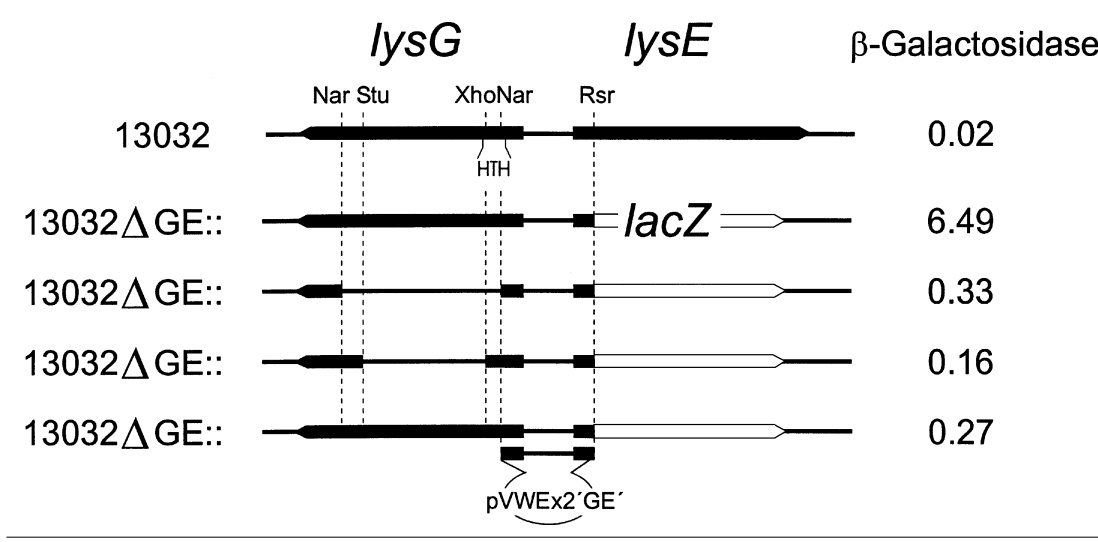

Fig. 1. Transcriptional lysE"lacZ fusions integrated in the chromosome to monitor the effects of lysG on lysE expression. The general arrangement of the locus is given at the top, together with the location of the helix-turn-helix (HTH) motif within LysG and the restriction enzyme sites used for the constructions. The fusions were integrated into the wild-type deleted of its original lysGE locus (13032 $\Delta \mathrm{GE})$ at the $p p c$ downstream site useful for this purpose (Vašicová et al., 1998). Plasmid pVWEX2' $\mathrm{GE}^{\prime}$ is a multicopy plasmid carrying the intergenic lys $G-l y s E$ region. The $\beta$-galactosidase activities are given in $U$ (mg protein) ${ }^{-1}$ and were determined after growth of the cells for $5 \mathrm{~h}$ on complex medium.

nificantly reduced, $\beta$-galactosidase activity. This could indicate the formation of a truncated peptide still interacting with target sequences.

To obtain further evidence that LysG is required for $l y s E$ expression, plasmid pVWEx2' GE' was constructed (Fig. 1). On its 455 bp insert, this multicopy plasmid contains the intergenic region between $l y s G$ and $l y s E$ which is assumed to contain the LysG binding site. With plasmid pVWEx2'GE' in strain 13032 $4 \mathrm{GE}:$ :lysGE'lacZ, a reduced $\beta$-galactosidase activity of $0.27 \mathrm{U} \mathrm{mg}^{-1}$ was the result. Thus the intergenic fragment titrates LysG away. This experiment identifies the intergenic region as its binding site. Determinations of the intracellular amino acid concentrations ensured that in these experiments, in which cells had been grown on complex medium BHI, L-lysine was present in all strains in high concentrations of about $60 \mathrm{mM}$.

\section{Transcript initiation sites of lysE and lysG}

To define the transcript initiation sites of the regulatory gene and its target gene, a fragment of 198 bp carrying the 70 bp intergenic $l y s G-l y s E$ region together with the $5^{\prime}$ ends of both genes was amplified and cloned into the promoter-probe vector pET2 (Vašicová et al., 1998). As expected, this fragment conferred chloramphenicol resistance on C. glutamicum in both orientations through expression of the cat reporter gene. The position of the $l y s E$ and $l y s G$ transcript initiation sites was localized in several primer-extension experiments, using fluoresceinlabelled primers which were hybridized to $30 \mu \mathrm{g}$ RNA isolated from C. glutamicum clones harbouring plasmid pET2PlysE or plasmid pET2PlysG. Two fluorograms of these experiments, together with the sequencing reactions carried out in parallel, are shown in Fig. $2(\mathrm{a}, \mathrm{b})$. This defines $\mathrm{C}_{1024}$ and $\mathrm{G}_{969}$ (on the opposite strand) in sequence X96471 as the transcript initiation sites for $l y s E$ and $l y_{s} G$, respectively. The two promoters overlap and share a palindromic sequence of $10 \mathrm{bp}$, labelled 'ABS' (for activating binding site) in Fig. 2(c), which could be an activation binding site of LysG. The transcript initiation site of $l y s E$ is in close proximity to the deduced translation initiation site, as inferred from sequence comparisons (Vrljić et al., 1999). Apparently lysE belongs to those genes of C. glutamicum for which the transcript does not provide a ribosome-binding site (Morbach et al., 2000). This seems to be a more general feature of the Actinomyces subdivision of Gram-positive bacteria to which C. glutamicum belongs (Strohl, 1992).

\section{Intracellular basic amino acids induce lysE expression}

As already mentioned, the specific $\beta$-galactosidase activities presented in Fig. 1 were quantified in strains grown on complex medium BHI. When we determined the activity in strain $13032 \Delta \mathrm{GE}:$ : lysGE'lacZ grown on mineral salts medium CGXII (Keilhauer et al., 1993), a drastically reduced specific activity of only $0.3 \mathrm{U} \mathrm{mg}^{-1}$ was obtained. The marked difference was present at all time points assayed during the growth curve (not shown). Only when grown into the late stationary phase on CGXII, after overnight incubation, did the specific activity increase to $2 \cdot 8 \mathrm{U} \mathrm{mg}^{-1}$. Therefore, in growing cells, the activity is only about $1 / 20$ th of that of cells grown on complex medium (Fig. 1). This indicates, on the one hand, a tight regulation of $l y s E$ expression and, on the other hand, the involvement of an inducer, possibly an amino acid, present in cells grown on BHI. This is in agreement with the notion that almost all LTTR-type transcriptional activators require an inducer in order to become active (Schell, 1993).

To assay for a specific intracellular increase in amino acids, we used the addition of peptides, some of which are known to be taken up and hydrolysed by $C$. glutamicum (Erdmann et al., 1993). The dipeptides used are given in Table 2. They contained the basic amino acids Lys, Arg, Cit (L-citrulline) and His. The Thr- and Phe-containing peptides served as controls. These peptides were added at a concentration of $0.5 \mathrm{mM}$ to salt medium CGXII, and, after growth of strain 13032 $\Delta \mathrm{GE}$ : : lys GE'lacZ for $4 \mathrm{~h}$, intracellular amino acid concentrations were determined by silica-oil centrifu- 
(a)

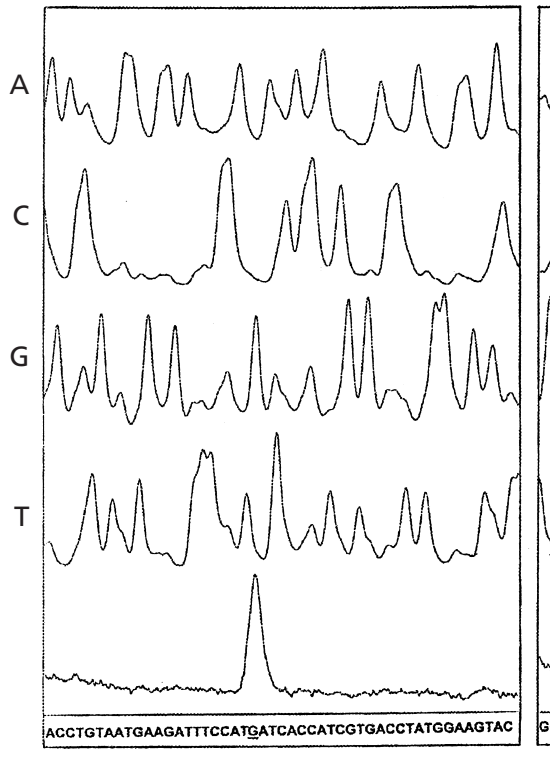

(c)

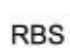

(b)

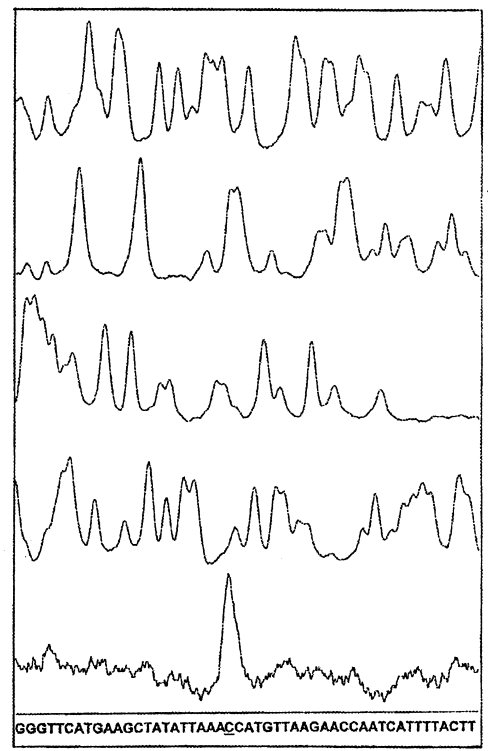

CCAGTTGAATGGGGTTCRTGAAGCTATATTAAACCATGTTAAGAACCAATCATIITACITARGTACTTCCATAGGTCACGATGGTGATCATGGAAATCT GGTCARCTTACCCCAAGTACTTCGATATAATTTGGIACAATTCTTGGTTACT AAAATGAATTCATGAAGGTATCCAGTGCTACCACTAGTACCTTTAGAA

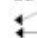

lysG

Fig. 2. Result of the primer-extension analyses and overview of the intergenic lysGlysE region (bp 936-1035 of sequence X96471). In (a), the primer-extension analysis of the lysE transcript is shown, and in (b) that of lys $G$ is presented. The corresponding fluorograms of the sequence determinations are shown, and the bottom curve shows the product of the primer extension. The residues identified on the coding strand of the respective transcriptional start sites are given underneath the fluorograms and are underlined. In the overview (c), the start of the transcript is indicated by a wavy line, and the polypeptides are indicated by the straight lines. The consensus promoter sequences are underlined. Boxed and labelled 'RBS' is a dyad element which is the putative recognition binding site of LysG. Boxed and marked 'ABS' is a palindrome which is a putative activating binding site involved in the induction of lysE expression.

Table 2. Specific amino acid (aa) increase, as obtained by peptide addition, and the resulting $\beta$-galactosidase activities

Peptide was added at a concentration of $0.5 \mathrm{mM}$, and intracellular determinations, as well as specific enzyme determinations, were performed after growth of the cells for $4 \mathrm{~h}$ on mineral salts medium. After $5 \mathrm{~h}$, comparable values were determined.

\begin{tabular}{|c|c|c|c|c|}
\hline \multirow[t]{3}{*}{ Peptide added } & \multicolumn{3}{|c|}{ Intracellular aa concentration $(\mathrm{mM})$} & \multirow{3}{*}{$\begin{array}{l}\text { Specific } \beta \text {-galactosidase } \\
\text { activity }\left(\mathrm{U} \mathrm{mg}^{-1}\right)\end{array}$} \\
\hline & \multirow[t]{2}{*}{ Peptide-specific aa } & \multicolumn{2}{|c|}{ Other aa } & \\
\hline & & Ala & Phe & \\
\hline None & - & 3 & $<1$ & $0 \cdot 3$ \\
\hline Lys-Ala & 42 Lys & 3 & $<1$ & $5 \cdot 5$ \\
\hline Arg-Ala & 98 Arg & 4 & $<1$ & $4 \cdot 2$ \\
\hline Cit-Phe & 73 Cit & 2 & 3 & $4 \cdot 1$ \\
\hline His-Ala & $18 \mathrm{His}$ & 3 & $<1$ & $3 \cdot 2$ \\
\hline Thr-Ala & $32 \mathrm{Thr}$ & 4 & $<1$ & $0 \cdot 3$ \\
\hline Ala-Phe & 4 Phe & 5 & - & $0 \cdot 3$ \\
\hline
\end{tabular}

gation. The specific $\beta$-galactosidase activities were quantified in extracts made from the same culture. As shown in Table 2, a specific increase in the intracellular Lys, Arg, Cit, His and Thr concentrations was obtained, whereas with Phe no strong increase was present. The Ala concentration was comparable in all strains and was not substantially increased, indicating that it is rapidly metabolized. All the other peptide-specific amino acids quantified (for instance Thr or Phe in the cells supplied with Lys-Ala) were at concentrations below $1 \mathrm{mM}$ (not shown). A high $\beta$-galactosidase activity, elevated 11-18fold relative to the controls, was present when the concentration of Lys, Arg, Cit or His was increased. This is evidence that these basic amino acids might serve as inducers of $l y s E$ expression. With the strain carrying the NarI deletion construct of lysGE'lacZ in its chromosome (Fig. 1) being used as a control, the specific $\beta$ galactosidase activities in cells grown under identical 


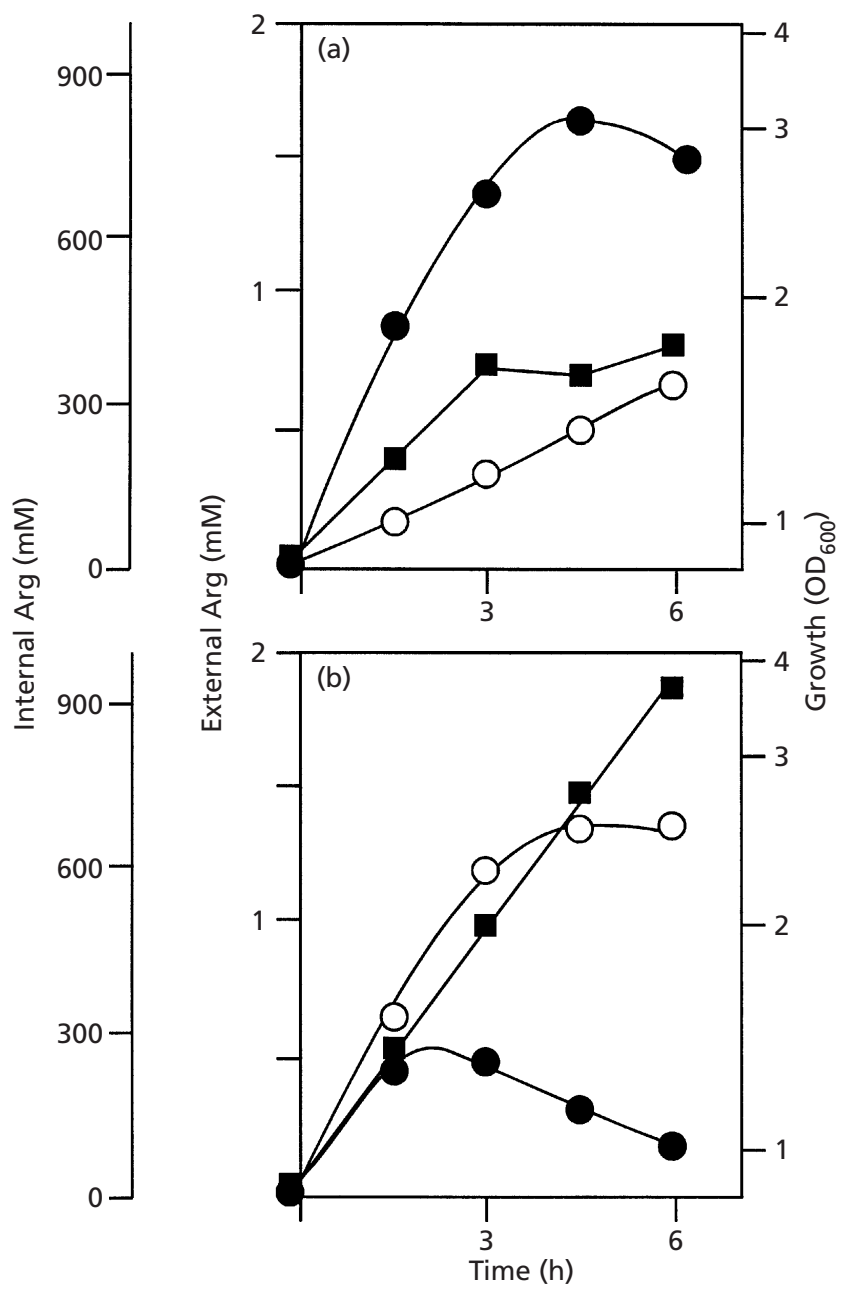

Fig. 3. Characteristics of strains $13032 \Delta E G$ (a) and 13032 (b) when incubated with the peptide $2 \mathrm{mM}$ arginyl-alanine. Because of the deletion, intracellular L-arginine (O) accumulates, growth $(\boldsymbol{\square})$ is prevented, and excretion of extracellular L-arginine $(O)$ is strongly reduced.

conditions to those given in Table 2 were $0 \cdot 2-$ $0 \cdot 3 \mathrm{U} \mathrm{mg}^{-1}$. This clearly indicates that LysG is required, together with one of the four basic amino acids, for $l y s E$ expression, and that no additional regulator, other than LysG, is present in the cell able to interact with Lys, Arg, His or Cit and capable of binding upstream of the fusion.

To address the question of the intracellular level of Llysine required for induction, we used different Lys-Ala concentrations. The highest specific $\beta$-galactosidase activity $\left(7 \cdot 2 \mathrm{U} \mathrm{mg}^{-1}\right)$ was present upon the use of $0.75 \mathrm{mM}$ peptide containing the extremely high intracellular L-lysine concentration of $225 \mathrm{mM}$ (not shown). Note that at $42 \mathrm{mM}$ L-lysine, the activity was already $5.5 \mathrm{U} \mathrm{mg}^{-1}$ (Table 2). However, attempts to correlate expression levels with the intracellular L-lysine concentration failed, since the intracellular concentration is not freely selectable in the course of an experiment (Erdman et al., 1993). We therefore used an entirely different approach to assay lysine-dependent lysE expression. For this purpose we used a pair of strains of C. glutamicum differing only in their aspartate kinase activity, which is the key enzyme of cellular Llysine synthesis (Cremer et al., 1991). In strain MH20$22 \mathrm{~B}$, the aspartate kinase is not feedback-inhibited by L-lysine, and the strain therefore has an elevated intracellular L-lysine concentration (Bröer et al., 1993); the isogenic strain LE4, however, carries the feedbacksensitive wild-type aspartate kinase (Schrumpf et al., 1992). The lysGE'lac-fusion cassette was introduced into these two strains, which were grown on minimal medium CGXII for the determination of enzyme activities and internal amino acid concentrations. The resulting $\beta$-galactosidase activity in strain $\mathrm{MH} 20-22 \mathrm{~B}$ was $6 \cdot 1 \mathrm{U} \mathrm{mg}^{-1}$ at a cytosolic L-lysine concentration of $35 \mathrm{mM}$, whereas the activity in strain LE4 was $0.4 \mathrm{U} \mathrm{mg}^{-1}$ at a cytosolic L-lysine concentration of $0.5 \mathrm{mM}$. In the cassette-less strains, assayed as controls, almost identical L-lysine concentrations were determined. This shows that intracellularly synthesized Llysine also induces lysE expression and that a concentration of $35 \mathrm{mM}$ L-lysine is already sufficient to obtain a 20-fold induction.

\section{LysE exports L-arginine and L-lysine}

lysE was isolated as the gene encoding the L-lysine export carrier (Vrljic et al., 1996). In view of the finding that $l y s E$ is induced by several basic amino acids, we studied the specificity of LysE in terms of its catalytic activity, and first focused on L-arginine as a possible exported cytoplasmic solute. In a growth experiment the behaviour of wild-type strain 13032 and strain $13032 \Delta \mathrm{EG}$ was studied. When $2 \mathrm{mM}$ of the peptide Arg-Ala was added to the mutant, after an intial doubling, growth was arrested, which was not the case with the wild-type (Fig. 3). Determination of the intracellular L-arginine concentration revealed its very high accumulation (up to $823 \mathrm{mM}$ ) relative to the wildtype $(245 \mathrm{mM})$. These characteristics are in accord with the known growth-inhibiting effects of high intracellular L-lysine concentrations (Vrljić et al., 1996). It illustrates that LysE also exports L-arginine, but does not exclude induction of a second exporter during the growth experiment. However, when the export activity was quantified over a $1 \mathrm{~h}$ period directly after inoculation, the efflux rate for L-arginine in the deletion mutant was below $0.01 \mathrm{nmol} \mathrm{min}{ }^{-1}$ (mg protein) ${ }^{-1}$ (not shown). This is of the order of the efflux mediated by passive diffusion (Vrljić et al., 1996) and thus shows that, under these conditions, LysE is the only relevant system for $\mathrm{L}^{-}$ arginine and L-lysine export present in C. glutamicum.

A more direct approach for proving the specificity of LysE towards L-arginine and L-lysine was to apply a competition experiment, i.e. measure the efflux when these two amino acids were present at comparable concentrations in the cell. To achieve this metabolic situation, we carried out a set of short-term experiments 

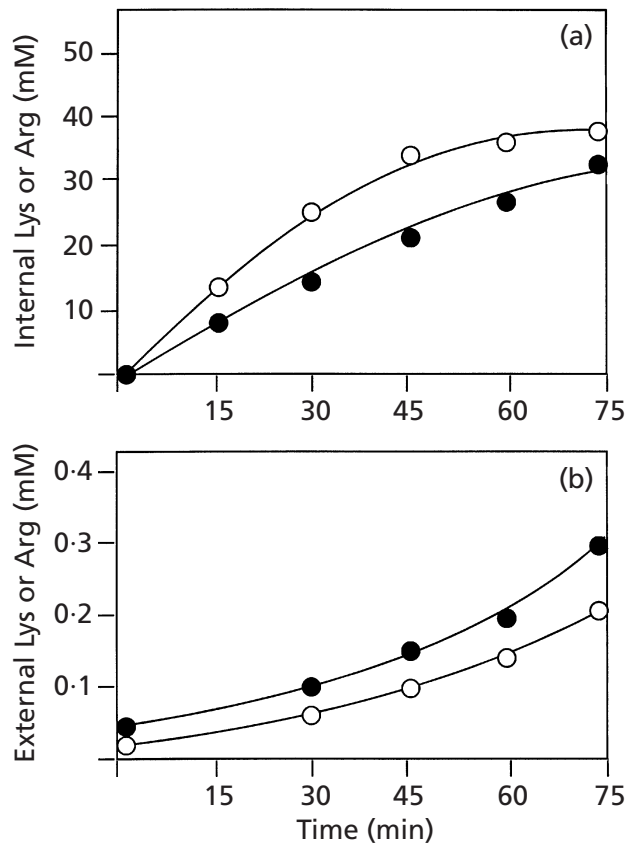

Fig. 4. Competition for L-lysine and L-arginine export in the wild-type. (a) Because of the addition of $2.72 \mathrm{mM}$ lysyl-alanine and $1.28 \mathrm{mM}$ arginyl-alanine, comparable intracellular concentrations of L-lysine ( $)$ and L-arginine (O) are obtained. (b) The extracellular accumulation for both amino acids is almost identical. ๑, L-Lysine; $\bigcirc$, L-arginine.

with the C. glutamicum wild-type by using different mixtures of Lys-Ala and Arg-Ala, in which the L-lysine and L-arginine content of the peptide mixture was varied systematically (not shown). At concentrations of $2.72 \mathrm{mM}$ Lys-Ala and $1.28 \mathrm{mM}$ Arg-Ala, after a $1 \mathrm{~h}$ incubation period we obtained an equal intracellular concentration of the two basic amino acids. Under these conditions, the intracellular L-lysine and L-arginine concentrations were increased to 34 and $38 \mathrm{mM}$ (Fig. $4 a)$, respectively, and the kinetics of the intracellular and extracellular amino acid concentrations was monitored. The time-courses of the extracellular accumulation of $\mathrm{L}-$ lysine and L-arginine were almost identical (Fig. 4b). This clearly indicates that the LysE export system accepts and transports both amino acids at a similar rate, and might indicate a comparable affinity towards L-lysine and L-arginine. The export rates calculated

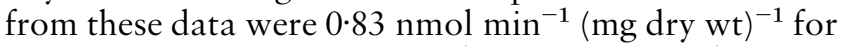
L-lysine, and $0.70 \mathrm{nmol} \mathrm{min}^{-1}(\mathrm{mg} \text { dry } \mathrm{wt})^{-1}$ for $\mathrm{L}^{-}$ arginine.

\section{L-Histidine and L-citrulline are exported by transport systems different from LysE}

We were also interested in studying whether His and Cit are also exported by LysE. Similarly to above, we used short-term experiments to compare the C. glutamicum wild-type with the deletion mutant 13032 $\Delta \mathrm{EG}$. We found that the addition of $2 \mathrm{mM}$ His-Ala resulted in
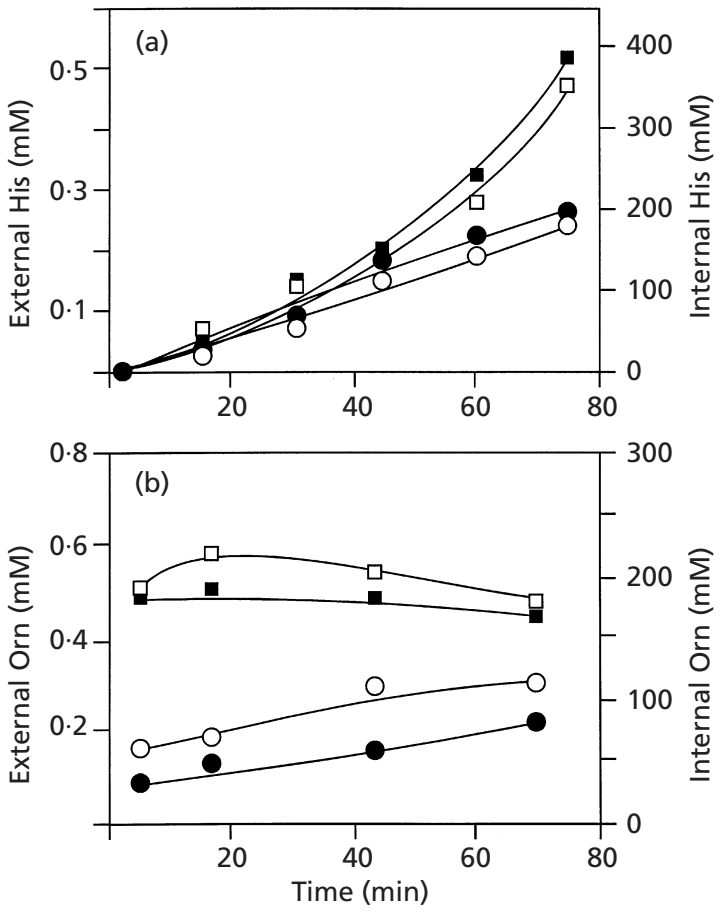

Fig. 5. (a) Intracellular (circles) and extracellular (squares) Lhistidine concentrations in 13032 and its deletion mutant, $13032 \Delta E G$, in the presence of $2 \mathrm{mM}$ histidyl-alanine. Open symbols represent the deletion mutant, and solid symbols represent the wild-type. (b) Intracellular (squares) and extracellular (circles) L-ornithine concentrations in 13032 with disrupted $\arg F$, along with those in the same strain with overexpressed lysE. The open symbols represent the strain with overexpressed lysE, and the solid symbols represent the control.

comparable export of L-histidine by both strains (Fig. $5 a)$. Without the addition of His-Ala, no amino acid excretion occurred (not shown). This shows, on the one hand, that L-histidine can in fact be exported by $C$. glutamicum if present at high intracellular concentrations, but, on the other hand, that LysE is not involved in the export of this amino acid. Although it could be argued that in the wild-type LysE exports His, and that in the deletion mutant a second exporter takes over the role of LysE, the simplest explanation of this experiment is that LysE does not accept L-histidine as a substrate. This is a remarkable result in view of the fact that we have shown that L-histidine might act as an inducer of LysG (Table 2). However, a similar situation exists for the LAO uptake system of E. coli (Wissenbach et al., 1995). Here it was shown that the system is induced by L-lysine, L-arginine and L-ornithine, but that it is only able to take up L-lysine and L-ornithine. The calculated export rate for L-histidine of C. glutamicum

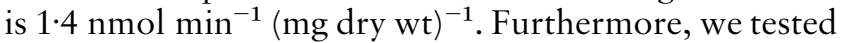
a Cit-Phe dipeptide in this kind of assay. Under similar experimental conditions, an intracellular accumulation of about $150 \mathrm{mM}$ L-citrulline was obtained. Compared to the C. glutamicum wild-type, however, the lysE deletion mutant did not exhibit reduced L-citrulline 
export, and efflux in the range observed for L-histidine occurred (not shown).

Other structurally related basic amino acids which could be transported by LysE are DL-diaminopimelate and Lornithine. However, specific peptides were not available (as in the case of DL-diaminopimelate), or they were found not to be hydrolysed (as in the case of Orn-Orn and Orn-Asp). Therefore, we disrupted $\arg F$, the gene encoding the ornithine carbamoyltransferase, in the chromosome of the wild-type (see Methods). This resulted in a mutant requiring $\mathrm{L}$-arginine for growth and which accumulated $60 \mathrm{mM}$ L-ornithine in the medium within $24 \mathrm{~h}$ (not shown). This $\operatorname{argF}$ mutant was transformed with pEC7lysE, overexpressing $l y s E$. In shortterm fermentation experiments, the L-ornithine concentrations obtained with the $\arg F$ mutant in the absence and the presence of overexpressed $l y s E$ were determined. As can be seen from Fig. 5(b), in both strains the intracellular L-ornithine concentration reached about $200 \mathrm{mM}$, whereas it was below $1 \mathrm{mM}$ in the wild-type (not shown). The ornithine export rate was $0.6 \mathrm{nmol} \mathrm{min}^{-1}$ (mg dry wt) ${ }^{-1}$ and was not increased by overexpressing lysE. We therefore conclude that LysE is not responsible for L-ornithine export, but that the Lornithine export of C. glutamicum is catalysed by a separate exporter. The presence of an L-ornithine exporter is in accord with known producer strains of C. glutamicum for this amino acid (Choi et al., 1995).

In a similar approach using chromosomal gene inactivation, we derived a strain suitable for assaying for the capacity of LysE to accept intracellular DL-diaminopimelate as a substrate. A C. glutamicum lys A mutant preventing the decarboxylation of DL-diaminopimelate to L-lysine was constructed. This mutant accumulated up to $1600 \mathrm{mM}$ DL-diaminopimelate in the cytoplasm (results not shown). However, in the medium, only concentrations of about $3 \mathrm{mM}$ accumulated within $2 \mathrm{~d}$, with the wild-type and with the lysE-overexpressing strain as well. This shows that LysE does not accept the basic amino acid DL-diaminopimelate as a substrate. Furthermore, it strengthens the belief that the basic amino acids have an extremely low permeability via the lipid bilayer of C. glutamicum.

\section{DISCUSSION}

The functional data obtained with the lac $Z$ fusions in which most of $l y s G$ was deleted, and those obtained with plasmid pVWEx2'GE' titrating LysG away such that it was unable to bind to the $l y s E^{\prime} l a c Z$ promoter are in full accord with the requirement of the LysG protein for the induction of $l y s E$ expression. This establishes LysG as a positive regulator of $l y s E$ transcription. Sequence identities of LysG, its gene arrangement with respect to its target gene, and additional features of the LysG interacting sites (see below) identify LysG of C. glutamicum as an LTTR-type regulator (Schell, 1993). The identification of the transcript initiation sites of $l y s G$ and $l y s E$ locate the perfect palindrome (-TAC-
TTAAGTA-) directly in the middle of the intergenic regions where both promoter regions overlap (Fig. 2). This palindrome probably represents the activating binding site characteristic of LTTR-regulated genes. A second dyad element present is the recognition binding site (RBS), which was selected by analogy to other LTTR systems (McFall et al., 1998). Both elements share the inverted repeats -TAAGT- and -TACTT- within or directly adjacent to them; these could represent DNA contact sites for LysG protein. The transcription initiation sites identified allow us to locate the translation initiation site of the LysE polypeptide more precisely. It shifts the initiating methionine that we previously inferred from the sequence further downstream to the following methionine, which is only three aminoacyl residues away at nt 1025-1027 (Vrljić et al., 1996).

As inducers of $l y s E$ for mediating transcriptional activation by LysG, L-lysine and L-arginine, as well as Lhistidine and L-citrulline, were identified. One of the very few LTTR regulators for which an attempt has been made to quantify the intracellular inducer concentration is NhaR. This regulator controls the synthesis of the $\mathrm{Na}^{+} / \mathrm{H}^{+}$antiporter of $E$. coli. It is known that it is fully induced at an extracellular $\mathrm{Na}^{+}$concentration of $50 \mathrm{mM}$ (Dover et al., 1997), when the intracellular $\mathrm{Na}^{+}$ concentration is around $60 \mathrm{mM}$ (Harel-Bronstein et al., 1995). With the C. glutamicum wild-type derivative carrying the $l y s E^{\prime} l a c Z$ fusion, a specific $\beta$-galactosidase activity of $5.5 \mathrm{U}$ at a concentration of $42 \mathrm{mM}$ (Table 2) was obtained and an activity of $6.5 \mathrm{U}$ was obtained at an intracellular L-lysine concentration of about $60 \mathrm{mM}$ (Fig. 1). This fits very well with the values obtained with C. glutamicum $\mathrm{MH} 20-22 \mathrm{~B}(5.8 \mathrm{U}$ at $35 \mathrm{mM})$. Even higher values of $7 \cdot 2 \mathrm{U}$ were achieved (not shown), but these values were not given consideration since growth was already retarded at the extraordinarily high internal concentration of $225 \mathrm{mM}$ L-lysine. In summary, these data indicate that a comparatively moderate L-lysine concentration of around $30-40 \mathrm{mM}$ is sufficient for almost full induction of lysE. The range of induction obtained is about 20-fold (see Table 2). Such strong control might be required to prevent expression of the export carrier under conditions in which L-lysine is synthesized from glucose, otherwise the viability of the cell would be endangered. In any case, L-lysine and Larginine, and also L-histidine and L-citrulline, act as inducers (though the latter two amino acids are not exported by LysE). This differential specificity of LysG and LysE is not unexpected, since both proteins, of course, have entirely different structures. A wide range of different inducer structures is known for the LTTR NahR of salicylate-degrading pseudomonads (Cebolla et al., 1997).

The affinity of LysE towards L-lysine and L-arginine is comparable. The other basic amino acids assayed ( $\mathrm{L}-$ histidine, L-citrulline, L-ornithine, DL-diaminopimelate) are not accepted as transport substrates by LysE. Basic amino acid exporters in other bacteria have not yet been identified. The uptake carrier of Penicillium chrysogenum accepts L-arginine, L-lysine and L-ornithine as 
substrates (Hillenga et al., 1996). E. coli has at least five importers for basic amino acids, which have different specificities. Three of them exhibit a high substrate affinity. Similarly, the lysine importer of C. glutamicum encoded by lysI (Seep-Feldhaus et al., 1991) has a $K_{\mathrm{m}}$ of $10 \mu \mathrm{M}$ for lysine (Bröer \& Krämer, 1991). Obviously, a high substrate affinity is reasonable for carriers transporting amino acids into the cell, as it allows the cell to cope with low substrate concentrations in the environment. However, it would be harmful for amino acid exporters, because of the inevitable loss of these metabolites when synthesized from carbohydrates. Accordingly, the $K_{\mathrm{m}}$ of LysE of C. glutamicum for L-lysine is three orders of magnitudes higher $(20 \mathrm{mM})$ than that of the importer (Bröer \& Krämer, 1991).

However, it should be borne in mind that in particular metabolic situations, for instance when intracellular Larginine is low and L-lysine high, co-export of $\mathrm{L}$-arginine by the lysine exporter, which would be active under these conditions, would be disadvantageous for the cell. This scenario possibly explains why $\operatorname{argS}$ and $l y s A$ in $C$. glutamicum form an operon (Marcel et al., 1990). The gene $\operatorname{argS}$ encodes the arginyl-tRNA synthetase and $l y s A$ encodes the DL-diaminopimelate decarboxylase, which is the only specific gene of L-lysine synthesis. Both Larginine and L-lysine control expression of this operon (Oguiza et al., 1993); this might serve to counteract intracellular amino acid imbalances possibly arising from the action of the lysine exporter.

In 1979 and 1982, Payne and coworkers had already observed the formation of amino acids derived from peptides with E. coli and Streptococcus faecalis, respectively (for a review, see Payne \& Smith, 1994). Thus, export of amino acids is a general phenomenon and there is now firm evidence that in E. coli and, in particular, in C. glutamicum, distinct transporters catalysing amino acid export are present (Krämer, 1994). For instance, in C. glutamicum export of L-isoleucine and L-threonine (Palmieri et al., 1996) is also a carriermediated process, and, as indicated in the present work, further transport systems specific for the export of at least L-citrulline, L-histidine and L-ornithine are present in C. glutamicum. In E. coli, it has been shown that overexpression of $r h t B$ results in increased extracellular accumulation of L-homoserine, and that $r h t C$ overexpression confers resistance to L-homoserine lactone (Zakataeva et al., 1999). It may be assumed, however, that the physiological function of $r h t B$, as well as the functions of its four paralogues present in E. coli, might be to serve cell-to-cell communication. Consequently, the observed amino acid export in E. coli might be due to limited specificity. Similarly, L-cysteine export in $E$. coli is probably due to limited specificity of the exporter YdeD (Daßler et al., 2000). In contrast, the function of LysE of C. glutamicum is obviously to control the intracellular L-lysine and L-arginine pools. This is in line with the fact that C. glutamicum is unable to use these amino acids for catabolic purposes. In combination with LysG, the whole system is designed to sense and export intracellular L-lysine and L-arginine. The cell is therefore able to respond to imbalances in cytosolic amino acid pools. These might occur both physiologically under particular environmental conditions (during growth in the presence of peptides) as well as during amino acid production.

\section{ACKNOWLEDGEMENTS}

We thank Professor W. Wohlleben (Tübingen) for extending hospitality to M. Pátek, who carried out the primer-extension experiments in his laboratory. This work was part of a project financed by Degussa-Hüls AG.

\section{REFERENCES}

Aleshin, V. V., Zakataeva, N. P. \& Livshits, V. A. (1999). A new family of amino-acid-efflux proteins. Trends Biochem Sci 24, 133-135.

Börmann, E., Eikmanns, B. J. \& Sahm, H. (1992). Molecular analysis of the Corynebacterium glutamicum gdh gene encoding glutamate dehydrogenase. Mol Microbiol 6, 317-326.

Bröer, S. \& Krämer, R. (1991). Lysine excretion by Corynebacterium glutamicum. 2. Energetics and mechanism of the transport system. Eur J Biochem 202, 137-143.

Bröer, S., Eggeling, L. \& Krämer, R. (1993). Strains of Corynebacterium glutamicum with different lysine productivities may have different lysine excretion systems. Appl Environ Microbiol 59, 316-321.

Cebolla, A., Sousa, C. \& de Lorenzo, V. (1997). Effector specificity mutants of the transcriptional activator NahR of naphthalene degrading Pseudomonas define protein sites involved in binding of aromatic inducers. J Biol Chem 272, 3986-3992.

Choi, D., Ryu, W., Chung, B. H., Hwang, S. \& Park, Y. H. (1995). Effect of dilution rate on continuous production of L-ornithine by an arginine auxotrophic mutant. J Ferment Bioeng 80, 97-100.

Cremer, J., Eggeling, L. \& Sahm, H. (1991). Control of the lysine biosynthetic sequence in Corynebacterium glutamicum as analyzed by overexpression of the individual corresponding genes. Appl Environ Microbiol 57, 1746-1752.

Daßler, T., Maier, T., Winterhalter, C. \& Böck, A. (2000). Identification of a major facilitator protein from Escherichia coli involved in efflux of metabolites of the cysteine pathway. Mol Microbiol 36, 1101-1112.

Dover, N., Higgins, C. F., Carmel, O., Pinner, A. R. \& Padan, E. (1997). $\mathrm{Na}^{+}$-induced transcription of nhaA, which encodes an $\mathrm{Na}^{+} / \mathrm{H}^{+}$antiporter in Escherichia coli, is positively regulated by nhaR and affected by hns. J Bacteriol 178, 6508-6517.

Eggeling, L., Oberle, S. \& Sahm, H. (1996). Improved L-lysine yield with Corynebacterium glutamicum: use of dapA resulting in increased flux combined with growth limitation. Appl Microbiol Biotechnol 49, 24-30.

Eikmanns, B. J., Follettie, M. T., Griot, M. U. \& Sinskey, A. J. (1989). The phosphoenolpyruvate carboxylase gene of Corynebacterium glutamicum: molecular cloning, nucleotide sequence, and expression. Mol Gen Genet 218, 330-339.

Eikmanns, B., Kleinertz, E., Liebl, W. \& Sahm, H. (1991). A family of Corynebacterium glutamicum/Escherichia coli shuttle vectors for gene cloning, controlled gene expression, and promoter probing. Gene 102, 93-98.

Erdmann, A., Weil, B. \& Krämer, R. (1993). Lysine secretion by wild-type Corynebacterium glutamicum triggered by dipeptide uptake. J Gen Microbiol 139, 3115-3122. 
Grant, S. G. N., Jessee, J., Bloom, F. R. \& Hanahan, D. (1990). Differential plasmid rescue from transgenic mouse DNAs into Escherichia coli methylation-restriction mutants. Proc Natl Acad Sci US A 87, 4645-4649.

Harel-Bronstein, M., Dibrov, P., Olami, Y., Pinner, E., Schuldiner, S. \& Padan, E. (1995). MH1, a second-site revertant of an Escherichia coli mutant lacking $\mathrm{Na}^{+} / \mathrm{H}^{+}$antiporters regains $\mathrm{Na}^{+}$ resistance and a capacity to excrete $\mathrm{Na}^{+}$in a $\Delta \mu_{\mathrm{H}+}$-independent fashion. J Biol Chem 270, 3816-3822.

Hillenga, D. J., Versantvoort, H. J. M., Driessen, A. J. M. \& Konings, W. N. (1996). Basic amino acid transport in plasma membrane vesicles of Penicillium chrysogenum. J Bacteriol 178, 3991-3995.

Keilhauer, C., Eggeling, L. \& Sahm, H. (1993). Isoleucine synthesis in Corynebacterium glutamicum: molecular analysis of the ilvBilvN-ilvC operon. J Bacteriol 175, 5595-5603.

Klingenberg, M. \& Pfaff, E. (1977). Means of terminating reactions. Methods Enzymol 10, 680-684.

Krämer, R. (1994). Secretion of amino acids by bacteria: physiology and mechanism. FEMS Microbiol Rev 13, 75-79.

Leuchtenberger, W. (1996). Amino acids - technical production and use. In Products of Primary Metabolism: Biotechnology, vol. 6, pp. 455-502. Edited by H. J. Rehm \& G. Reeds. Weinheim: VHC.

Liebl, W., Bayerl, A., Stillner, U. \& Schleifer, K. H. (1989). High efficiency electroporation of intact Corynebacterium glutamicum cells. FEMS Microbiol Lett 65, 299-304.

McFall, S. M., Chugani, S. A. \& Chakrabarty, A. M. (1998). Transcriptional activation of the catechol and chlorocatechol operons: variations on a theme. Mol Microbiol 223, 257-267.

Marcel, T., Archer, J. A. C., Mengin-Lecreulx, D. \& Sinskey, A. J. (1990). Nucleotide sequence and organization of the upstream region of the Corynebacterium glutamicum lys A gene. Mol Microbiol 4, 1819-1830.

Morbach, S., Junger, C., Sahm, H. \& Eggeling, L. (2000). Attenuation control of ilvBNC in Corynebacterium glutamicum: evidence of leader peptide formation without the presence of a ribosome binding site. Biosci Biotechnol Biochem 90, 501-507.

Oguiza, J. A., Malumbres, M., Eriani, G., Pisabarro, A., Mateos, L. M., Martin, F. \& Martin, J. F. (1993). A gene encoding arginyltRNA synthetase is located in the upstream region of the lys A gene in Brevibacterium lactofermentum: regulation of argS-lys A cluster expression by arginine. J Bacteriol 175, 7356-7362.

Palmieri, L., Berns, D., Krämer, R. \& Eikmanns, M. (1996). Threonine diffusion and threonine transport in Corynebacterium glutamicum and their role in threonine production. Arch Microbiol 165, 48-54.

Payne, J. W. \& Smith, M. W. (1994). Peptide transport by microorganisms. Adv Microb Physiol 36, 2-80.

Peters-Wendisch, P. G., Kreutzer, C., Kalinowski, J., Pátek, M., Sahm, H. \& Eikmanns, B. J. (1998). Pyruvate carboxylase from Corynebacterium glutamicum: characterization, expression and inactivation of the pyc gene. Microbiology 144, 915-927.

Schäfer, A., Kalinowski, J., Simon, R., Seep-Feldhaus, A. \& Pühler, A. (1990). High-frequency conjugal plasmid transfer from Gramnegative Escherichia coli to various Gram-positive coryneform bacteria. J Bacteriol 172, 1663-1666.
Schäfer, A., Tauch, A., Jäger, W., Kalinowski, J., Thierbach, G. \& Pühler, A. (1994). Small mobilizable multi-purpose cloning vectors derived from the Escherichia coli plasmids pK18 and pK19: selection of defined deletions in the chromosome of Corynebacterium glutamicum. Gene 145, 69-73.

Schell, M. A. (1993). Molecular biology of the LysR family of transcriptional regulators. Annu Rev Microbiol 47, 597-626.

Schrumpf, B., Eggeling, L. \& Sahm, H. (1992). Isolation and prominent characteristics of an L-lysine hyperproducing strain of Corynebacterium glutamicum. Appl Microbiol Biotechnol 37, 566-571.

Seep-Feldhaus, A. H., Kalinowski, J. \& Pühler, A. (1991). Molecular analysis of the Corynebacterium glutamicum lysI gene involved in lysine uptake. Mol Microbiol 5, 2995-3005.

Simon, R., Priefer, U. \& Pühler, A. (1983). A broad host range mobilization system for in vivo genetic engineering: transposon mutagenesis in Gram negative bacteria. Bio/Technology 11, 784-791.

Strohl, W. R. (1992). Compilation and analysis of DNA sequences associated with apparent streptomyces promoters. Nucleic Acids Res 20, 961-974.

Vašicová, P., Abrhámová, Z., Nešvera, J., Pátek , M., Sahm, H. \& Eikmanns, B. (1998). Integrative and autonomously replicating vectors for analysis of promoters in Corynebacterium glutamicum. Biotechnol Tech 12, 743-746.

Vrljić, M., Eggeling, L. \& Sahm, H. (1995). Unbalance of L-lysine flux in Corynebacterium glutamicum and its use for the isolation of excretion defective mutants. J Bacteriol 177, 4021-4027.

Vrljić, M., Sahm, H. \& Eggeling, L. (1996). A new type of transporter with a new type of cellular function: L-lysine export from Corynebacterium glutamicum. Mol Microbiol 22, 815-826.

Vrljić, M., Garg, J., Bellmann, A., Wachi, S., Freudl, R., Malecki, M. J., Sahm, H., Kozina, V. J., Eggeling, L. \& Saier, M. H., Jr (1999). The LysE superfamily: topology of the lysine exporter LysE of Corynebacterium glutamicum, a paradigm for a novel superfamily of transmembrane solute translocators. $J \mathrm{Mol}$ Microbiol Biotechnol 1, 327-336.

Wendisch, V. (1997). Physiological investigations and studies by NMR spectroscopy on the central metabolism of different recombinant Corynebacterium glutamicum strains. $\mathrm{PhD}$ thesis, University of Düsseldorf.

von Wilken-Bergmann, B., Tils, D., Sartorius, J., Auerswald, E. A., Schröder, W. \& Müller-Hill, B. (1986). A synthetic operon containing 14 bovine pancreatic trypsin inhibitor genes is expressed in E. coli. EMBO J 5, 3219-3225.

Wissenbach, U., Six, S., Bongaerts, J., Ternes, D., Steinwachs, S. \& Unden, G. (1995). A third periplasmic transport system for Larginine in Escherichia coli: molecular characterization of the artPIQMJ genes, arginine binding and transport. Mol Microbiol 17, 675-686.

Zakataeva, N. P., Aleshin, V. V., Tokmakova, I. L., Troshin, P. V. \& Livshits, V. A. (1999). The novel transmembrane Escherichia coli proteins involved in the amino acid efflux. FEBS Lett 452, $228-232$.

Received 16 January 2001; revised 15 March 2001; accepted 26 March 2001. 